\title{
Coronary heart disease: dietary links and pathogenesis
}

\author{
Serge Renaud ${ }^{1, *}$ and Dominique Lanzmann-Petithory ${ }^{2}$ \\ 'INSERM, Unity 330, University Bordeaux 2, 146, rue Léo Saignat, 33076 Bordeaux Cedex, France: \\ ${ }^{2}$ Department of Internal Medicine, Nutrition and lipid metabolism. Henri Mondor Hospital, 51. Avenue, Marechal \\ de Lattre deTassigny, 94010 Creteil Cedex, France
}

\begin{abstract}
For decades it has been postulated that the main environmental factor for coronary heart disease (CHD) was the intake of saturated fatty acids (SFA). Nevertheless, confirmation of the role of SFA in CHD through intervention trials has been disappointing. It was only when the diet was enriched in n-3 fatty acids that CHD was significantly prevented, especially cardiac death.

In addition to n-3 fatty acids, many other foodstuffs or nutrients such as fibers, antioxidants, folic acid, calcium and even alcohol contribute to prevent CHD. Thus the relationship between diet and CHD morbidity and mortality appears to be much more complex than formerly suspected considering as key factors only SFA, linoleic acid, cholesterol and atherosclerosis. Some of the mechanisms are briefly described, but many additional nutrients (or non nutrients) may also play an important role in the pathogenesis of CHD.

Finally, as a result of the most recent epidemiologic studies the ideal diet may comprise: $8 \%$ energy from SFA, 5\% from polyunsaturated fatty acids with a ratio 5/1 of linoleic/alpha-linolenic acid+longer chains n-3, oleic acid as desired, large intake of cereals, vegetables, legumes and fruits, fish twice a week, cheese and yogurt as dairy products, rapeseed and olive oils as edible fat. Without side effects, such a diet can be highly palatable, easily enjoyed by many populations and may prevent effectively and rapidly (within a few weeks or months) CHD.
\end{abstract}

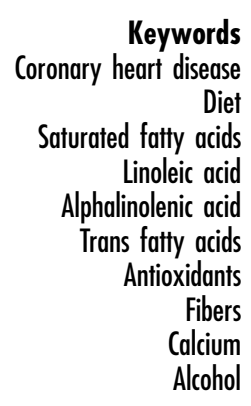

\section{Introduction}

Pathologists at the end of last century (Virchow, Ignatowski, Anitschkow) have observed that in human atherosclerotic lesions, there were large amounts of cholesterol deposits. When they fed rabbits with human food including cholesterol, they observed in arteries, lesions somewhat similar to human atherosclerosis. That was the starting point of the diet-heart hypothesis.

\section{Saturated fatty acids, cholesterol and CHD: epidemiology}

\section{Cross-population studies}

Already in 1930's it was known that all populations with a high intake of saturated fats, presented atherosclerosis and coronary heart disease (CHD). However it was the Seven Countries Study ${ }^{1}$ that clearly demonstrated that saturated fatty acids (SFA) were the main environmental factor for CHD.

Moreover, the Japan - Honolulu - San Francisco study $^{2}$, confirmed that the relationship between the intake of fat and CHD mortality was not due to genetic factors but rather to the diet per se. Many other epidemiologic studies (cited elsewhere ${ }^{3}$ ) confirmed the specificity of the association between diet and CHD.

In the Seven Countries Study, the most recent report indicates that even after 25 years follow-up ${ }^{4}$, the CHD mortality is still closely and directly related to the intake of saturated fats. All the individual SFA, lauric (12:0), myristic (14:0), palmitic (16:0) and even stearic acid (18:0) were positively and significantly related to CHD mortality $(r=$ 0.81 to $0.86, p<0.001)$. Nevertheless, because the intake of each of the SFA was closely related to the total intake of SFA, it was not possible to confirm that all these fatty acids (FA) were independently related to CHD. But the results were clear concerning the total fat intake versus that of SFA. Only the SFA were closely related to CHD. That demonstration is illustrated by the comparison between Crete and EastFinland, the two extreme in hard coronary events, 26 in Crete and 1074 in East-Finland (age standardized rate per 10 000). The total intake of fat was $40 \%$ of energy in Crete and 39\% in East-Finland, while the intake of SFA was $8 \%$ in Crete and 22\% in East-Finland. 


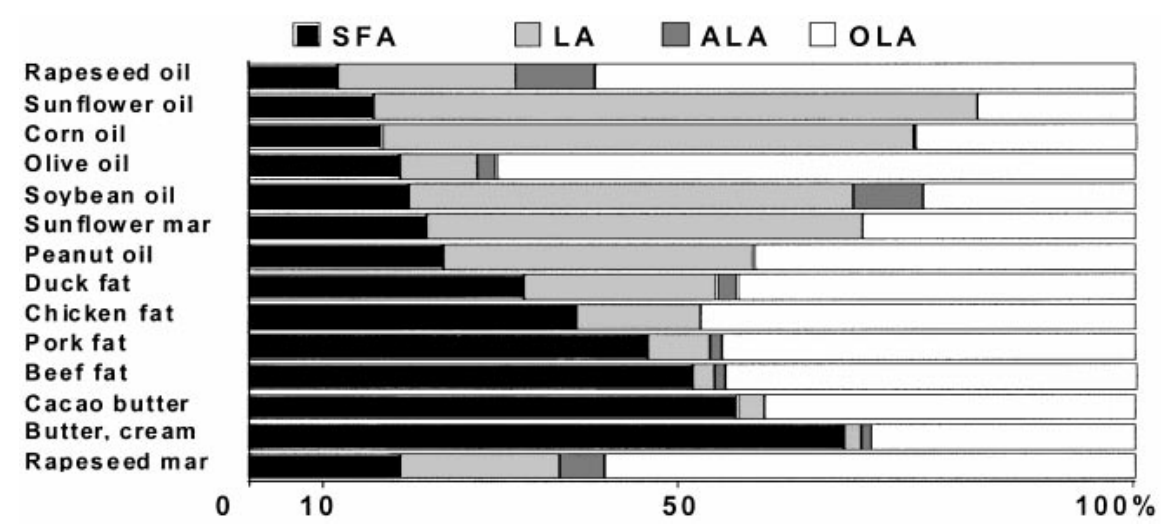

Fig. 1 Fatty acid composition of common fats. Rapeseed mar: rapeseed margarine used in the Lyon study ${ }^{9,10}$. SFA $=S a t u r a t e d$ fatty acids $\mathrm{LA}=$ Linoleic acid, $\mathrm{ALA}=$ Alpha - linolenic acid, OLA = Oleic acid

\section{Within-population studies}

They have the disadvantage of a limited variation between individuals in their habitual dietary intake. Their advantage is to be able to adjust for confounding factors such as blood pressure, smoking, body weight and others, that contribute to CHD. As reviewed recently ${ }^{5}$, out of 10 of these studies, 5 have observed a positive significant relationship between the intake of SFA and CHD including the recent Belgium study on 21500 subjects ${ }^{6}$.

In addition, in the Western Electric Study ${ }^{7}$, even if CHD was not significantly and independently related to the intake of SFA, it was related to the Keys equation that includes SFA, polyunsaturated fatty acids (PUFA) and cholesterol in the diet. In the Zutphen study in Netherlands, no significant relationship was found with the intake of SFA but there was an association with the intake of cholesterol ${ }^{8}$. Thus, it can be concluded that the majority of prospective epidemiologic studies have observed a close relationship between the intake of SFA (or cholesterol) and CHD. For these reasons, the intake of SFA should be reduced to approximately $8 \%$ of energy, the level in Crete $^{1}$ (the greatest life expectancy in the Western World), in Japan (the greatest life expectancy in the World) and in the recent intervention trial ${ }^{9,10}$ in Lyon.

\section{Dietary fat and CHD: experimental studies}

\section{Atherosclerosis}

As reviewed elsewhere ${ }^{11}$, experimental studies have been conducted in animals to determine to what extent dietary fats, especially saturated fats, could induce atherosclerosis and CHD. However in many studies, saturated fats were associated with a high concentration of cholesterol, making it difficult to evaluate the specific contribution of the different fats, especially the respective role of FA. Results were also different depending on whether different natural oils were compared with multiple differences in the level of fatty acids as well as in their position in the glycerol molecule. FA in the sn-2 position of dietary triglycerides are preferentially absorbed through the intestinal wall while those in sn-1,3 position are released in the intestinal tract and partly excreted in the feces through the formation of calcium soaps ${ }^{12}$. Thus, FA in position 2 of dietary triglycerides play a crucial role in the metabolism and biologic effects of these FA as we have shown recently ${ }^{13}$. It may explain observations that did not appear logical without this knowledge. As an example, it may explain why lard seems to be much more atherogenic than reflected by its whole FA composition (Fig. 1). Contrarily to many other fats, more than $65 \%$ of the palmitic acid contained in lard is in sn-2 position. This palmitic acid from lard is readily absorbed and metabolized which is not the case for many other animal fats (Fig. 2).

To solve those problems in experimental studies in animals, FA were esterified by methanol instead of glycerol. The results obtained in rabbits indicate that methyl stearate was more atherogenic than methyl oleate $^{14}$.

In further studies, Kritchevsky and Tepper, to evaluate the atherogenic effect of individual SFA given under the form of natural dietary fats, interesterified corn oil with either 12:0, 14:0, 16:0 or 18:0. The results were fats with the same amount of SFA in the 3 positions of the triglycerides. Under those conditions in rabbit, all SFA were more atherogenic than corn oil, the most atherogenic being 12:0 and 16:0. Of interest was that 18:0 was associated with a lower serum cholesterol than corn oil, but was more atherogenic.

In addition to rabbits, many other animal species have been used to induce atherosclerosis. It seems that the most relevant to human may be the studies in monkeys. Among the most recent studies are those in African Green monkeys fed $40 \%$ of energy as fat, comparing the effect of lard to safflower oil (n-6 FA) or to menhaden oil (n-3 FA) ${ }^{15}$. These studies confirmed that lard (saturated fat) was associated with higher serum cholesterol and much higher severity of intimal lesions than safflower and especially menhaden oil. 


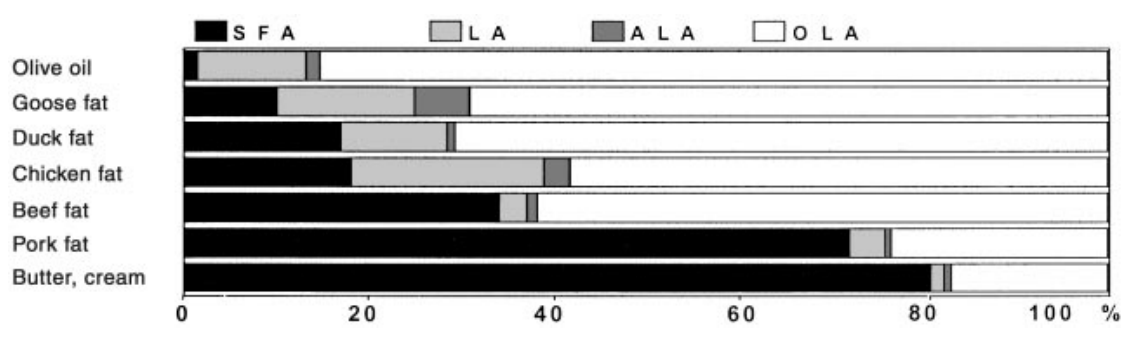

Fig. 2 Fatty acids in sn-2 position of common fats. Abbreviations as in Fig. 1. In sn-2 position pork and dairy fats are very similar, extremely rich in SFA in sn-2 position. By contrast, poultry fats have mostly OLA in sn-2 position. Thus, poultry fats may have comparable atherogenic effects, to that of olive oil, while pork fat and dairy fat may be very similar in terms of atherogenicity

In conclusion, experimental studies in different animal species, as briefly reviewed above, seem concordant in that the most hyperlipidemic dietary fats, in general those rich in SFA, are also the most atherogenic, perhaps with the exception of 18:0. This is an important observation since it has been speculated that the intake of 18:0 may not be predisposing to CHD as the other SFA. The role of 18:0 will be examined further in relation to thrombosis.

\section{Thrombosis}

Atherosclerosis induced in animal studies by feeding saturated fats and cholesterol, was in practice never associated with the main human complications of atherosclerosis i.e. coronary thrombosis and sudden death. Specific studies to investigate the relationship between saturated fats and thrombosis have shown consistent results even if only a few Investigators have been involved in such studies, years ago.

In 1965, Nordoy, using a standardized damage of the jugular vein, reported that feeding hydrogenated coconut oil and cholesterol to rats increased the incidence of thrombus formation ${ }^{16}$. The addition to the diet of linseed oil rich in alpha-linolenic acid (ALA), significantly reduced the incidence of thrombosis, even when thrombosis was initiated by injection of adenosinediphosphate (ADP) ${ }^{17}$. In 1969, Renaud and Godu ${ }^{18}$, have succeeded in inducing large thrombi by epinephrine or endotoxin, in rats fed a thrombogenic diet rich in SFA. In these studies, it was consistently found that the long-chain SFA (16:0 and 18:0) were the most thrombogenic FA, a result similar to that obtained by Hornstra and Vendelmans ${ }^{19}$ also in rat, but in a completely different model. In the Hornstra model the least thrombogenic fat was canola oil, rich in ALA $^{19}$.

Contrarily to the atherogenic effects of dietary fats mostly related to their hypercholesterolemic effects, the thrombogenic effect of a fat, at least in the model used ${ }^{20}$, was neither related to its degree of saturation or its hypercholesterolemic effect. The thrombogenicity of a dietary fat was related to its content in long-chain SFA, specially stearic acid (18:0) the FA the most effective in inducing platelet aggregation and thrombus formation in vitro and in vivo ${ }^{21}$. The tendency to develop thrombosis in rat was closely associated with platelet hyperaggregability and a shortened clotting time essentially related to the platelet clotting activity, primarily dependent on the membrane phospholipids. Both the aggregability and the platelet clotting activity were related to the FA composition of the platelet phospholipids ${ }^{22}$.

In conclusion, in animals it seems that dietary SFA, independently of serum cholesterol, induce a tendency to thrombosis, at least in part through the modification of platelet membranes in their FA composition. In that connection, 18:0 may be the most damaging SFA, a result that has to be confirmed by human studies, directly on CHD, but not only on its effects on blood lipids. In the Lyon study ${ }^{10}$, the only SFA significantly lower in plasma of the experimental group markedly protected from CHD, was stearic acid. For these reasons and although further human studies are required in that connection, we cannot consider as confirmed the hypothesis that the intake of stearic acid is safe in relation to CHD, even if it does not increase serum cholesterol.

\section{Sudden cardiac deatb}

Sudden cardiac death is one of the most dramatic clinical manifestations of CHD associated with thrombosis induced ischemia. It is caused by ventricular fibrillation and has been reproduced in $\operatorname{dogs}^{23}$ and rats $^{24,25}$. While the risk of fibrillation seems to be increased in rat by feeding meat or animal fat, it can be prevented, both in dog and rat, by infusion or feeding of n-3 FA. Even in vitro, on neonatal rat myocytes in cultures, addition of $n-3$ fatty acids completely inhibited the calcium induced arrhythmia, an effect not reproduced by either SFA or oleic acid (OLA) ${ }^{25}$. In rat at least, the most efficient n-3 FA to prevent arrhythmia seems to be the precursor of the family, ALA (18:3 n-3), as supplied by rapeseed (canola) oil $(n-6 / n-3=2.6)$, but not by soybean oil $(n-6 / n-3=$ $9)^{25}$. This effect was not reproduced by other oils such as olive and sunflower oils, i.e. by other FA. The mechanism of the antiarrhythmic effects of n-3 FA, in normal and $\mathrm{Ca} 2+$ overloaded cells, appears to be primarily by reducing the $\mathrm{Ca} 2+$ entry $^{26}$.

\section{Trans fatty acids and CHD: Epidemiologic and experimental studies}

Trans fatty acids (TFA) can be found naturally in small 
amounts (2-7\%) in dairy products and meats, but occur mostly in partially hydrogenated vegetable oils.

In the 1940's in USA, two-thirds of the visible fat consumed was from animal and one third from vegetable origin. In the 1960's, two thirds were from vegetable and one third from animal origin.

These changes resulted in a significant increase in the level of TFA both in tub (11-28\%) and in hard margarines (19-49\%) as well as in shortenings coming from partially hydrogenated vegetable oils ${ }^{27}$. Those changes occurred under public pressure to reduce the intake of animal and other saturated fats.

Recent evaluation of the TFA consumption in the US put the figure at $8.1 \mathrm{~g} /$ person $/ \mathrm{day}^{27}$, even $9.6 \mathrm{~g}$ representing 2-5\% energy. By contrast in Europe $^{28}$, the intake of TFA ranged from $1.2 \mathrm{~g}$ /day in Greece to $6.7 \mathrm{~g} /$ day in Iceland. It was 1.6 in Portugal, 2.3 in Finland, 2.4 in Germany, 2.7 in France, 2.8 in UK, 2.9 in Denmark, 4.4 in Belgium and 4.8 in Norway. In Europe, it was only in Finland, Iceland, the Netherlands, Norway and UK that the main source of TFA was partially hydrogenated oils and fats. In the other countries, especially Italy, France and Germany, 75 to $78 \%$ of TFA were derived from natural animal sources (milk and ruminant fat).

In recent years, a large prospective study on the effect of TFA in 85095 female nurses was reported ${ }^{29}$, with 431 cases of CHD. After adjusting for 11 confounding variables, the relative risk (RR) was 1.16 (95\% CI $0.81-$ 1.55), for the second quintile compared to the first quintile; 0.99 (0.69-1.43), for the third; 1.16 (0.80-1.70) for the fourth and $1.47(0.98-2.20)$ for the fifth quintile, with a significant trend $(p=0.0006)$ for increasing risk. Therefore in this study, there was a significant positive association between the intake of TFA and CHD

It was further estimated ${ }^{30}$ that an increase of $2 \%$ of energy from TFA would result in a 93\% increase in the risk of CHD while a $5 \%$ increase in SFA would only result in a $17 \%$ increase risk of CHD. Such an association has not been found in other studies ${ }^{31}$ and debates are still going on, on whether TFA are more harmful than SFA.

As to the mechanism involved in the possible deleterious effects of TFA on CHD, all the recent clinical studies indicate that TFA consumption (from 3.8 to $11.2 \%$ energy) is associated with increased concentration of serum cholesterol and LDL cholesterol, with an unchanged HDL cholesterol or slight decrease. At the same time, a decrease in the ratios of LDL/HDL or serum cholesterol/HDL cholesterol was noted. In addition, four recent studies reported that TFA were increasing $\mathrm{Lp}(\mathrm{a})$ concentration $^{31}$.

As to whether TFA influence the severity of atherosclerosis in animal studies, seven different studies were reported by Nicolosi $^{32}$ in rabbits, pigs and vervet monkeys. In none of these studies there was any increase in the risk of atherosclerosis whatever was the level of TFA included in the diet (from $3.2 \%$ or $6.0 \%$ trans in the diet with $14 \%$ fat given to vervet monkeys ${ }^{33}$ to $50 \%$ TFA in the $17 \%$ fat diet given to pigs) ${ }^{34}$. Thus in experimental models of atherosclerosis tested, there was little evidence that dietary TFA caused the development of atherosclerosis, even fatty streaks. Therefore, there is a striking difference, from the experimental point of view, between the atherogenic effect of SFA and that of TFA. Of course, negative effect does not mean that there is no effect. For example in the studies with monkeys ${ }^{33}$ there was very little difference in serum cholesterol between the controls and the animals given the TFA diet. Thus in that study a higher level of atherosclerosis could not be expected in the group with TFA. On the other hand in the rabbit studies of Weigensberg et al. ${ }^{35}$ the animals given TFA had a higher level of cholesterol in blood but the severity of atherosclerosis was similar to that of controls.

As concluded by Nicolosi ${ }^{32}$ additional studies in various animal models for long periods of time are needed because of the chronic nature of atherosclerosis. In addition, further experimental work should include effects on platelets, thrombosis and ventricular fibrillation.

In conclusion, as emphasized by Martijn $\operatorname{Katan}^{36}$ the fact that a few epidemiologic studies found a positive association between TFA and CHD deserves attention. 'By themselves these data fall far short of proving that high intakes of TFA promote CHD but the effects of TFA on plasma lipoproteins lend some credence to a causal link'. Nevertheless, since the intake of TFA in Europe is much lower than in USA, especially than in the Nurses Health Study $^{29,30},(0.5-2.1 \%$ energy vs 2 to $5 \%)$, the intake of TFA in Europe may not be as harmful as it has been found in USA. In addition, it is also a possibility that the TFA, derived from natural animal sources as it is the case in many European countries, may not be as noxious as the TFA resulting from oil hydrogenation, an hypothesis which has to be confirmed by further studies. In the Lyon diet heart study, TFA supplied less than 1\% energy, and spectacular protective effects on mortality and recurrences were observed ${ }^{9,10}$. Thus we are suggesting that TFA could supply up to $1 \%$ of energy, without obvious damaging effects.

\section{Nutrients with protective effects on CHD}

\section{Polyunsaturated fatty acids (PUFA)}

The linoleic (18:2 n-6) (LA) and alpha-linolenic (18:3 n-3) (ALA) acids are essential for normal growth and physiologic functions of all tissues. These FA have double bonds located respectively at six (n-6) and three (n-3) carbon atoms from the methyl group. Men and animals cannot include a double bond in position n-6 or n-3 i.e. synthesize the corresponding FA. Thus, those two FA are essential. However men and animals can add double bonds to these FA between the original double bonds and the carboxyl group. The carbon chain can also be elongated at the carboxyl end. These metabolic processes 
are responsible for the production of long chain (20-22 carbon atoms) metabolites with 3 to 6 double bonds. The result is the formation of two FA families ( $n-6$ and n-3), both essentials, competing for the same enzymatic systems. Thus, as already suggested ${ }^{37}$, they have to be supplied in food at a proper level, probably as a ratio of $3-5 / 1$, but not $10-20 / 1$ as encountered at present in many countries. Those FA are important components of membrane phospholipids involved in fluidity and deformability of membranes and even in the clotting activity of these membranes ${ }^{38}$. Among these FA, arachidonic and other FA with 18 to 20 carbon atoms are precursors of potent mediators such as prostaglandins and leukotrienes.

In addition, located in the membranes at the interface between the extracellular and intracellular compartment, they may influence intracellular signaling pathways. Arachidonic acid and its metabolites as a second messenger system, activate transcription factors and induce the expression of early genes as an immediate cellular response, that can be antagonized by the n-3 FA family ${ }^{39}$. Thus again, a physiologic balance of the two essential FA families has to be supplied in the food in relation to health in general. Because in vegetable oils, only LA lowers serum cholesterol as shown by many studies, recommendations to prevent CHD was to increase the intake of PUFA, essentially LA, to $10 \%$ of energy, by using oils and margarine containing mostly LA (sunflower oil, safflower oil, corn oil). We have observed $^{40}$ that at a high intake, LA blocks the conversion of ALA in its metabolites, a result confirmed by Emken ${ }^{41}$ using deuterium labeled LA and ALA.

Addition of a large amount of LA to a diet low in SFA to decrease serum cholesterol by $15 \%$ as in the Minnesota Coronary Survey ${ }^{42}$ did not prevent, in primary prevention, cardiovascular and all cause mortality. Even in secondary prevention, the use of soybean oil containing approximately 60\% LA and 8\% ALA, was not associated with a protection from cardiac death both in the Leren ${ }^{43}$ and Morris and Ball ${ }^{44}$ trials.

In rat, soybean oil did not prevent ventricular fibrillation (sudden death) ${ }^{25}$. Only rapeseed (canola) oil was efficient for that purpose, possibly owing to its ratio LA/ALA of 2.6/1 compared to 7.5/1 in soybean oil. By using rapeseed oil and margarine, we were able to completely prevent sudden death in our secondary prevention trial ${ }^{9}$ the ratio LA/ALA in the whole diet being $5 / 1$. Longer chain $n-3$ FA from fish oil may also prevent cardiac death to some extent as shown by the diet and reinfarction trial (DART) ${ }^{45}$.

In addition, recent prospective studies have shown that the only PUFA inversely related to CHD was ALA either on non-fatal ${ }^{46,47}$ myocardial infarction (MI) or on cardiac death $^{48}$. In that connection it has been observed that the FA lowering platelet aggregation in man was $\mathrm{ALA}^{49}$ but not LA that rather increases platelet response to ADP in rat, monkey and $\operatorname{man}^{50}$.
Finally, in the Lyon diet heart study ${ }^{51}$, in the experimental group having a much higher intake of ALA, the occurrence of cancers was reduced by $61 \%$, after a followup of 4 years. This suggests that in addition to CHD, other serious health problems such as cancer and inflammation $^{52}$, may require a change in the balance of LA/ALA.

Concerning the long chain n-3 FA (EPA, DHA) it has been suggested that the low rates of CHD in Greenland and in Japan may be due to the high consumption of fish in these countries ${ }^{53}$. This hypothesis has been supported by prospective studies showing in most of them that the subjects with a moderate intake of fish at baseline, had a lower risk of fatal CHD compared to men who did not consume any fish ${ }^{54,55}$. These observations have been confirmed by intervention trials such as the DART ${ }^{45}$ and the GISSI ${ }^{56}$ trials on the prevention of cardiac death. Mechanisms involved, as reviewed by Leaf and Weber ${ }^{57}$, include a lowering of very low-density lipoproteins (VLDL), of thromboxane production and of blood viscosity associated with an increase in fibrinolytic activity and in prostacyclin synthesis. As already emphasized, the protection from sudden cardiac death may be by reducing the Ca2+ entry in myocytes ${ }^{26}$.

In conclusion, both the n-6 and n-3 FA are essential for life, but have opposite effects on several systems and compete for the same enzymes. Thus for the prevention of CHD and other serious health problems, the dietary supply of PUFA should not be higher than 5\% energy with a proper ratio of the two families, probably in the range of 3-5/1 (LA/ALA+longer chain n-3) but not 10 to 20/1 as frequently observed in Western countries.

\section{Monounsaturated fatty acids (MUFA)}

The relative failure of LA to prevent CHD in intervention trials $^{42}$ as well as the possible carcinogenic ${ }^{58}$ and suppressive effects on the immune system ${ }^{59}$ have drawn attention to MUFA in the prevention of CHD. The Cretan population with the greatest life expectancy in the Western World ${ }^{1}$ and the lowest risk of CHD, has an extremely high intake of MUFA, essentially OLA (9-cis 18:1), as supplied by olive oil.

Earlier studies have considered OLA as a neutral $\mathrm{FA}^{60}$ neither raising nor lowering serum cholesterol. This neutral effect also extends to all lipoprotein fractions: VLDL, low density lipoprotein (LDL) and high density lipoprotein (HDL). That neutrality should not be considered as a disadvantage since very few nutrients can be considered totally safe. The concept of the neutrality of OLA can be extended to imply its safety. In terms of carcinogenicity or its effect on the immune system, OLA emerges as one of the safest nutrients ${ }^{61}$. Recent analyses ${ }^{62}$ suggest or confirm previous work in that OLA is not totally neutral on LDL-cholesterol, but rather exerts a significant lowering effect which is half as potent as LA. Moreover OLA increases the concentration of HDLcholesterol $^{63}$ slightly more than $\mathrm{LA}^{47}$. One reason for 
OLA to be associated with a lower LDL-cholesterol is that OLA is the preferred substrate for the ACAT (acyl CoA cholesterol acyltransferase). When the liver is enriched with OLA, an increase in the hepatic LDL receptor activity is observed, resulting in a reduction in the LDLcholesterol production rate and a drop in the LDLcholesterol level in blood.

In addition to have its concentration reduced by OLA, LDL enriched in OLA by supplement feeding in humans, presented lower proinflammatory properties ${ }^{64}$. That study demonstrates that when exposed to oxidative stress, the LDL enriched in OLA promotes less monocyte chemotaxis (52\% lower) and reduces monocyte adhesion by $77 \%$ compared with LA enriched LDL. LDL enriched in OLA may be less readily converted to proinflammatory minimally oxidized LDL, able to enhance early events of atherosclerosis such as monocyte chemotaxis and adhesion. Finally, OLA may enhance cholesterol efflux from human fibroblasts ${ }^{65}$

In addition to protective effects on atherosclerosis per se, an OLA rich diet seems also to have a beneficial effect on thrombogenesis. Compared to SFA rich diet, human subjects on a OLA enriched diet for 8 weeks, exhibited a significantly lower activation of postprandial factor VII and concentration of factor VII antigen ${ }^{66}$. The interest in factor VII is that it is positively associated with CHD mortality $^{67}$ and may be involved in the initiating mechanisms of coronary thrombosis.

Thus considering all the positive effects for health of a diet rich in OLA as briefly described above, it seems logical that such a diet can be associated with a low mortality rate from CHD. Nevertheless, for the type of huge protection observed in Crete (95 to 98\% compared to other countries) additional nutrients such as ALA, fibers, antioxidants and others may be required. Nevertheless, because of the safety of OLA as a nutrient, its intake may not be restricted in a healthy diet, except perhaps as a risk for overweight.

\section{Dietary fiber}

As reviewed by William Connor ${ }^{68}$, the fiber hypothesis has been developed by two physicians Dr Denis Burkitt and Dr HC Trowell both working at Kampala, in Uganda. They noted that the Africans they treated had rarely Western diseases such as CHD, hypertension, diabetes, cancer and others. They speculated that the reason was that the African diet contained a lot of roughage that had been eliminated of the Western diet.

It was discovered that soluble fibers such as pectin from fruits or beta-glucan in oat bran, lower serum cholesterol $^{69}$. However the effect on cholesterol seems to be extremely modest. Thus, it has been concluded that the main effect of oat bran consumption is to replace the high fat, high cholesterol foods usually consumed.

Nevertheless, recent prospective studies indicate that a higher intake of fibers from fruits, vegetables and cereals reduces the risk of mortality not only of $\mathrm{CHD}^{70}$, but also of cancer and all causes ${ }^{71}$.

In Finland ${ }^{72}$ a prospective study on 21930 smoking men, followed for 6.1 years, has observed that both nonfatal myocardial infarction and coronary death were inversely related to the intake of fiber, the association being higher with coronary death. For men in the highest quintile of dietary fiber $(34.8 \mathrm{~g} /$ day $)$ coronary death was reduced by $31 \%$ ( $p<0.001$ for trend) compared to the lowest quintile $(16.1 \mathrm{~g} /$ day $)$. Adjustment for confounding variables did not change the results.

The conclusion was that greater intakes of food rich in fiber, independently of other risk factors, substantially reduce the risk of CHD mortality. Soluble fibers and cereal fibers seemed to have the greatest effects.

In $\mathrm{USA}^{73}$, on 43757 US male health professionals followed for 6 years, fatal coronary disease and non-fatal MI were reduced by $41 \%$ among men in the highest quintile of fiber intake $(28.9 \mathrm{~g} /$ day) compared with men with the lowest quintile $(12.4 \mathrm{~g} /$ day). As in Finland, adjusting the results for confounding variables did not change much the significance of the data. Also as in Finland, the inverse association was strongest for fatal CHD and the cereal fibers were the most strongly associated with the reduced risk of CHD. As to the mechanism involved, the reduction in CHD observed in these last 2 prospective studies is larger than would be expected from the limited beneficial effect on serum cholesterol, especially for cardiac death. A high fiber intake has been associated with a decrease in the level of insulin and an increase in insulin sensitivity ${ }^{74}$. Effects on hemostatic variables have also been reported ${ }^{75}$.

Further studies are certainly required to elucidate the mechanisms involved in the remarkable protection observed in the prospective studies. Intervention trials seem to be required since the only intervention with fiber (in secondary prevention) did not observe any beneficial effect on $\mathrm{CHD}^{45}$. Nevertheless, the intake of fibers is certainly not associated with adverse effects and thus, their consumption should not be restricted but rather largely encouraged.

\section{Antioxidants}

The renewed interest for the putative protective effect of antioxidants on $\mathrm{CHD}^{76}$ comes from the Steinberg et al. hypothesis suggesting that it is the oxidatively modified LDL that are atherogenic. Studies in rabbits show that atherosclerosis can be reduced by adding an antioxidant to the diet, an effect independent of plasma cholesterol ${ }^{77}$. Free radicals are highly reactive molecules because they contain an unbound electron. In our body, they can oxidize many molecules such as lipids, especially unsaturated fatty acids (UFA). Under normal physiologic conditions, cells are protected against free radicals by enzymes (superoxide dismutase, catalase, glutathione peroxidase) and by antioxidants such as vitamin $\mathrm{E}$ (the 
main antioxidant in membranes), vitamin $\mathrm{C}$ and betacarotene. When the balance between the formation of free radicals and antioxidant defenses is disturbed, UFA from LDL are oxidized. Oxidized LDL become atherogenic eliciting a chemotactic response stimulating monocytes, to be transformed into macrophages and subsequently into foam cells. Oxidized LDL are cytotoxic and damage endothelial cells, stimulating platelet aggregation and procoagulant activity ${ }^{78}$. Finally, the susceptibility of LDL to oxidation appears to be related to the severity of coronary atherosclerosis in $\operatorname{man}^{79}$.

In LDL, all UFA are not susceptible to peroxidation at the same extent. LA appears to be much more susceptible than OLA $^{80}$. As to n-3 FA, it has been postulated that the long chain n-3 from fish oil (EPA, DHA) may inhibit rather than increase oxidative modification of $\mathrm{LDL}^{81}$, despite the number of double bonds in the molecules.

The next step in the antioxidant hypothesis of atherosclerosis is to determine whether dietary antioxidant substances are inversely related to CHD.

Prospective studies in 39910 male health professionals $^{82}$ and 87245 female nurses ${ }^{83}$ have observed that the incidence of CHD was about $40 \%$ lower in subjects who consumed vitamin E supplements. By contrast 3 European prospective studies ${ }^{84,85,86}$ in which vitamin $\mathrm{E}$ was supplied mostly by food, did not show an inverse relationship to $\mathrm{CHD}$. It has been postulated that the prevention of CHD requires large amounts of vitamins difficult to get from dietary sources alone.

Nevertheless, intervention studies with vitamin E supplements have not clarified further the problem. In the 'Cambridge Heart Antioxidant Study' (CHAOS) ${ }^{87}$ study on secondary prevention of CHD, 2002 patients were randomly assigned to a pharmacological dose of vitamin E or placebo. After 17 months, vitamin E reduced non fatal MI by $66 \%$ and cardiac death+MI by $36 \%$ respectively, in such a way that there was a non-significant increase in cardiovascular death in the treated group. In the ATBC trial in Finland, $50 \mathrm{mg}$ daily of vitamin E did not reduce $\mathrm{CHD}$ mortality or the incidence of angina pectoris in heavy smokers ${ }^{88}$.

Thus there are considerable doubts as to whether we know the dose and duration of vitamin E supplementation to effectively prevent CHD and whether a diet rich in vitamin E might not be more efficient than supplements. In that connection, it has been shown that a high concentration of vitamin $\mathrm{E}$ can act as prooxidant ${ }^{89}$, especially in the absence of aqueous antioxidants such as ascorbate and urate ${ }^{90}$. Polyphenols can be added as powerful antioxidants that also can regenerate vitamin E.

An example of the possible role of other antioxidants on the vitamin E status was the French adaptation of the Cretan diet ${ }^{9}$. Despite a lower intake of vitamin $\mathrm{E}$, the experimental group had a significantly higher plasma level of vitamin $\mathrm{E}$ at one year, related to the intake and the plasma level of vitamin C. Vitamin C is known to protect and regenerate vitamin $\mathrm{E}^{91}$ and the polyphenols may have a similar effect. Nevertheless, the intake of vitamin $C$ was not inversely related with $\mathrm{CHD}$, in the large prospective studies from Harvard ${ }^{110,111}$, contrarily to polyphenols in Netherlands $^{92}$ and Finland ${ }^{93}$ found to be beneficial.

To be noted is that the Cretan cohort (the greatest life expectancy in the Western World) had with the Corfu cohort the highest intake of vitamins C and E of the Seven Countries Study ${ }^{94}$, out of their local food. Although there is absolutely no doubt that in the human diet a high intake of vegetables and fruits with their antioxidant components, is associated with a consistent protection from CHD and other diseases, further studies are warranted to evaluate under what conditions antioxidant supplements may have similar beneficial effects. By contrast, in all populations with a high intake of vegetables and fruits, as well as in all studies having investigated the effects of such diets, beneficial effects were observed not only on CHD but also on other diseases. Thus, a high consumption of vegetables and fruits should be encouraged by any means.

\section{Folic acid, pyridoxine (vitamin B6)}

It has been known for years ${ }^{95}$ that an increased level of homocysteine in blood was associated with severe arteriosclerosis. Homocysteine is an amino acid produced in the metabolism of methionine, usually not detectable in plasma or urine. As a result of a genetic disorder, large amounts accumulate in plasma and urine and these patients die early of CHD. Even a moderately increased level of homocysteine in blood is associated with increased risk of peripheral vascular disease, $\mathrm{CHD}$ and stroke $^{96}$.

Enhanced platelet aggregation, endothelial damage ${ }^{97}$ and lipid peroxidation ${ }^{98}$ have been postulated as possible mechanisms in the predisposing effect of homocysteine to CHD.

To avoid accumulation of homocysteine in blood, homocysteine has to be converted to cysteine in a vitamin B6 dependent reaction or remethylated to methionine in a relation involving folic acid and vitamin B12. One efficient way to reduce homocysteinuria appears to be through administration of folic acid alone, or folic acid and pyridoxine combined ${ }^{99}$. In further studies, only folic acid or the combination with the $\mathrm{B}$ vitamins led to a significant reduction of homocysteine in plasma, but not vitamins $\mathrm{B} 12$ or $\mathrm{B} 6$ per $\mathrm{se}^{100}$.

In a recent prospective study, Rimm et al. ${ }^{101}$, have observed, in 80082 nurses after 14 years of follow-up, that the number of non fatal MI and fatal CHD were reduced by $45 \%$ in the highest quintile of both folic acid and vitamin $\mathrm{B} 6$ intake compared with the lowest quintile. $26 \%$ of folate was supplied by multiple vitamins and the rest by cereals, orange juice, lettuce, eggs, broccoli and other vegetables and fruits. A surprising result in this study was that the protective effect of folate and vitamin 
B6 was much more efficient in women consuming more than one drink of alcohol per day.

It has also been reported that n-3 fatty acids from fish oil reduced the level of homocysteine compared to olive oil $^{102}$. Thus it may be that other nutrients than vitamins may have an effect on homocysteine, a topic that requires much further studies.

\section{Calcium}

The interest of dietary calcium in relation to CHD is that in many countries, an inverse relationship has been found between hard water and the occurrence of cardiovascular diseases ${ }^{103,104}$. This effect appears to be due to the calcium content of the waters ${ }^{105}$.

In man dietary calcium is known to induce a borderline reduction of serum cholesterol ${ }^{106}$ but an $18 \%$ decrease in triglycerides has been noted $^{107}$. In studies on 9 groups of French and British farmers the intake of calcium evaluated by the chemical analysis of a duplicate sample of food including water consumed, was inversely related in multivariate analysis, to the level of triglycerides but not of cholesterol ${ }^{108}$. In the studies in $\operatorname{man}^{108}$ as well as in rabbits $^{109}$, the intake of calcium was strongly inversely related to thrombin induced platelet aggregation and platelet clotting activity. It seems that the intake of calcium was regulating the absorption of saturated fats and their effect on platelets. Possible mechanisms ${ }^{110}$ could be that dietary calcium promotes the excretion of SFA in the feces, especially the long chain SFA (16:0, 18:0) the most active to promote platelet aggregation and susceptibility to thrombosis in animals.

The National Health and Nutrition Examination Survey in USA, showed that a low calcium intake gives rise to high blood pressure ${ }^{111}$. In the Nurses Health Study ${ }^{112}$, results obtained were similar. An intake of $800 \mathrm{mg}$ calcium decreased the risk of high blood pressure compared to an intake of less than $400 \mathrm{mg} /$ day.

The National Institute of Health Continuing Medical Education recommends a daily intake of up to $2000 \mathrm{mg}$ of calcium per day to prevent hypertension. At that level, additional beneficial effects on triglycerides and platelet aggregation may be expected in subjects with a high intake of SFA. Thus, in all studies evaluating the relationship between the intake of SFA and occurrence of CHD, the intake of calcium from food and water has to be considered as a confounding factor in addition to the other risk or preventive factors.

Cheese are the richest foodstuffs in calcium but is also rich in SFA. Nevertheless, Greece and France, the highest consumers of cheese in the world, enjoy the highest life expectancy in the Western World. Studies suggest that the absorption of SFA from fermented dairy products (cheese, yogurt...), through the formation of insoluble calcium salts of SFA, partly excreted in the feces, is much lower than from whole milk, a structure designed for total absorption of all nutrients. In the Lyon study ${ }^{9,10}$ and also in the Finnish experiment ${ }^{113}$, consumption of cheese and yogurt was suggested, if possible, low in fat. Thus, consumption of cheese seems to be compatible with a low mortality rate from CHD, probably through the beneficial effect of calcium.

Finally, in all populations, an increased intake of calcium from food and water seems to be a justified recommendation for health.

\section{Alcobol}

The inverse relationship between morbidity and mortality from CHD and the moderate consumption of alcoholic beverages, has been documented by ecological, casecontrol and prospective studies involving more than 1 million subjects ${ }^{114}$. Depending on the prospective studies, with an intake of 2 to 4 drinks per day, reduction in CHD mortality was of 20 to $60 \%$. Only one study in Finland has shown an increase risk, whatever was the intake of alcohol $^{115}$. It has to be emphasized that in this Finnish study, $60 \%$ of the alcohol was spirits, that it was used for intoxication (binge drinking) and was followed by sudden death or stroke. Binge drinking of beer seems to have similar effect ${ }^{116}$ since after heavy acute intake a 6.5 fold increase in fatal MI was observed. It is known that alcohol could be beneficial for CHD only if used moderately and spread out over the week.

Rimm et al $^{117}$ found that the average number of days per week on which alcohol was consumed was inversely associated with the risk of CHD. Men who reported drinking on 3-4 days per week had a 34\% reduced risk of CHD compared with men who drank on less than one day. Thus, to have protective effect on health, particularly to prevent CHD, alcohol has to be used as in the Mediterranean countries, mostly at meals, through the week, and of course, moderately.

A question frequently raised is whether wine per se is healthier than other alcoholic beverages. On CHD as emphasized by Rimm et al. ${ }^{117}$, data so far do not confirm that wine protects more efficiently than other alcohols. In our recent prospective study in Eastern France ${ }^{118}$ on 36250 men, we found that the protective effect of wine may be more consistent than that of beer. It is mostly on cancer and death from all causes, at least in man, at very moderate intake, that wine appears to offer more protection than the other alcohols as also observed by Gronbaek et al. ${ }^{119,120}$, probably owing to phenolic compounds such as resveratrol ${ }^{121}$, contained in wine.

Concerning the mechanisms involved in the protective effect of alcohol, it has been associated with an increased level of HDL-cholesterol, independently of physical activity $^{122}$. However, it seems that the effect on HDL can explain only $50 \%$ of the protective effect of alcohol ${ }^{123}$.

To protect from CHD, the main target of alcohol seems to be MI i.e. coronary thrombosis rather than atherosclerosis per $\mathrm{se}^{124,125}$. In that connection the influence of alcohol drinking on platelet aggregation was examined in 
rat as well as in man and shown to be markedly reduced after moderate intake. However, under acute ingestion of ethanol, a rebound effect on platelet response can be observed that may explain the untoward effects of binge drinking resulting in sudden death and stroke ${ }^{126}$. This rebound effect on platelets does not seem to occur with wine drinking at least in rats, owing to the antioxidant polyphenols $^{127}$. It is known that alcohol drinking increases peroxidation that appears to be related to the rebound effect. The polyphenols from wine impede that peroxidation and the untoward effects of ethanol on platelets $^{125}$

Concerning the long-term effects of alcohol on platelets in man, we found in 1600 subjects from Wales, that the intake of alcohol in a dose-related manner, was inversely associated with the response of platelets, most significantly secondary aggregation to $\mathrm{ADP}^{128}$, probably through thromboxane A2 production ${ }^{129}$. This is exactly what aspirin does ${ }^{130}$, known also for its remarkable protective effects on $\mathrm{CHD}^{131}$. Thus, it is no longer surprising that a moderate intake of alcohol could be associated with a protective effects on CHD since it increases the level of HDL-cholesterol at about the same extent as physical activity ${ }^{122}$, and reduces platelet aggregation similarly to aspirin. Nevertheless, depending on the type of alcoholic beverage wine, beer, spirits and the way it is used (binge drinking or moderate consumption regularly at meals) opposite effects can be observed on CHD and other health problems. Thus recommendations should be similar to the 1995 US dietary guidelines for Americans: 'If you drink alcoholic beverages, do so in moderation, with meals and when consumption does not put you or others at risk ${ }^{132}$.

\section{Dietary fatty acids and serum cholesterol}

As shown in human and several animal species, feeding increasing amounts of cholesterol alone results only in modest increases in serum LDL-cholesterol or total cholesterol. By contrast, with a constant intake of cholesterol, increasing the amount of a triacylglycerol containing predominantly SFA, results in an increased response of serum cholesterol. This effect is suppressed if UFA replace the SFA of the triacylglycerol.

Thus, these observations indicate that cholesterol and LDL-cholesterol in blood are increased to some extent by the intake of cholesterol, but that it is predominantly the amount and type of fat which determine their blood level. To determine whether all SFA were equivalent to increase cholesterol in blood, FA from 6:0 to 18:0 were fed to hamsters $^{133}$. The shorter chain FA $(6: 0$ to 10:0) did not significantly elevate LDL-cholesterol in blood, compared to dietary cholesterol alone. These FA are rapidly metabolized to acetyl Co A in the liver, and do not change the FA composition of the lipid pools. By contrast the 12:0, 14:0 and 16:0 FA markedly increased the
LDL-cholesterol production and its concentration in plasma. By contrast, 18:0, although it became enriched in liver, did not change the production rate of 18:0 and did not alter the plasma level of LDL-cholesterol. Similar results were obtained in human studies. Thus it seems that the only FA biologically active concerning LDLcholesterol are 12:0, 14:0 and 16:0, while 18:0 is biologically neutral.

When 18:1 (9-cis) (OLA) was given to animals in the same studies as above, the LDL-cholesterol production rate was reduced as well as the LDL-cholesterol concentration. By contrast, the same FA with a trans configuration 18:1 (9-trans) (Elaidic acid) did not lower the plasma level of LDL-cholesterol.

Because early studies suggested that LA was more potent than OLA to lower serum cholesterol when compared to SFA, the first equations to calculate the effects of dietary FA on plasma total cholesterol, considered only SFA and PUFA.

Keys et $a l .{ }^{134}: \Delta \mathrm{TC}=1.2$ (2 SFA - PUFA), 18:0 being excluded from SFA.

Hegsted et al. ${ }^{135}: \Delta \mathrm{TC}=2.10$ SFA -1.16 PUFA

Recently these equations have been revisited taking into account the lowering effect of OLA (MUFA) and even of (18:0) stearic acid

Mensik and $\operatorname{Katan}^{136}: \Delta \mathrm{TC}=1.51$ SFA -0.12 MUFA 0.60 PUFA

$$
\Delta \mathrm{LDL}-\mathrm{c}=1.28 \mathrm{SFA}-0.24 \mathrm{MUFA}-0.55 \text { PUFA }
$$

Derr et al. ${ }^{137}: \Delta \mathrm{TC}=2.3(14: 0)+3.0(16: 0)-0.8$ $(18: 0)-1.0$ PUFA

$$
\Delta \mathrm{LDL}-\mathrm{c}=2.6(14: 0)+2.9(16: 0)-0.5(18: 0)-0.7
$$
PUFA

All these equations have been obtained in metabolic ward studies and are all consistent with our present knowledge. Nevertheless, they only give indications on the short term level of serum cholesterol (and LDLcholesterol) that can be expected from the dietary habits. They are not able to give the real risk of CHD since there are many additional factors involved in that risk.

$\mathrm{TC}=$ Total cholesterol

LDL-C=LDL-cholesterol

\section{Dietary prevention of CHD}

Once dietary risk factors are discovered, mechanism of their effects elucidated, before public health recommendations it still remains to test, in randomized intervention trials, the dietary factors involved to be reasonably certain of their eventual beneficial effects. It is only intervention trials that offer the best chance of directly answering whether or not diet can reduce the risk of CHD and other diseases. Soon after the discovery of the positive relationship between saturated fats and CHD, intervention trials were set up to verify through a relatively simple diet manipulation whether saturated fats were really the villain. In the 1960's two comparable secondary prevention 
trials were organized to prevent recurrences and death in 400 coronary patients each and lasted 5 years. The Leren trial $^{43}$ observed a significant lowering of coronary events but not of total mortality or sudden death. The Morris trial $^{44}$ although similar to the Leren trial in terms of diet modification and lowering of cholesterol (16\% for Morris vs $14 \%$ for Leren) did not observe a significant reduction either of coronary events or of cardiac or total mortality. The diet recommendations were to decrease as much as possible the intake of saturated fats and to use mostly soybean oil for preparing food. Apparently, the subjects were sticking to the diet since their cholesterol was lowered similarly in the 2 trials. In these studies, the polyunsaturated/saturated ratio $(\mathrm{P} / \mathrm{S})$ was increased from $0.2-0.3$ to more than 1.8 i.e. a large intake of PUFA to replace SFA.

A conclusion of these studies was that in secondary prevention, once the patients had already $\mathrm{CHD}$, it was too late to try to prevent by dietary manipulations coronary events and death since atherosclerosis is a long lasting pathologic process. Thus, additional trials in primary prevention were set up as briefly shown in Fig. 3. Of special interest was the primary prevention of the Minnesota Coronary Survey because the dietary changes were similar to the previous secondary trials with a $\mathrm{P} / \mathrm{S}$ ratio of 1.6 in the experimental group compared to 0.3 in the control group ${ }^{42}$. Also, it was a double blind randomized trial on 9057 subjects in psychiatric hospitals in Minnesota i.e. the ideal conditions for a trial. After 4.5 years of follow-up, serum cholesterol was lowered by $15 \%$ in the experimental group compared to controls, similarly to the Leren and Morris secondary trials.

Concerning coronary events and all-cause mortality, they were increased by $8 \%$ in the experimental group. These results do not suggest that diet, especially dietary SFA, are not related with CHD but rather that the type of diet proposed, not used by any population in the world, was not better to prevent CHD than the diet used in Western Countries at that time.

In the meanwhile, Hjermann and Leren in Oslo had settled an additional trial, this time in primary prevention, but in subjects at risk because they smoked and were hypercholesterolemic ${ }^{138}$.

The diet intervention was combined with a decrease in smoking but apparently the effect was due mainly to the dietary habits. In the experimental group coronary events were reduced by $44 \%$, cardiac death by $59 \%$, sudden death by $69 \%$, all cause mortality by $39 \%$ after a follow-up of 102 months. The diet recommendations were to decrease the intake of SFA without being replaced by PUFA, to use more bread, more vegetables, lean meat, more fishes and fruit for dessert. In the first report, the $\mathrm{P} / \mathrm{S}$ ratio mentioned for the experimental group was 1.01 with $8.2 \%$ of calories supplied by saturated fat. After reevaluation,

Prevention through increase in n-6 fatty acids

\begin{tabular}{|c|c|c|c|c|c|c|c|}
\hline Name, & year & (Ref) & Type, $N^{\circ}$ subjects & Intervention & $\begin{array}{l}\text { Serum } \\
\text { chol }\end{array}$ & $\begin{array}{l}\text { Total } \\
\text { mortality }\end{array}$ & $\begin{array}{l}\text { Non fatal } \\
\text { MII P P }\end{array}$ \\
\hline Leren, & 1970 & (43) & Secondary, 400 & $\uparrow \mathrm{P} / \mathrm{S} \quad(0.3-2.4)$ & $\downarrow 14 \%$ & N.S. & $\downarrow 23 \% \quad 0.05$ \\
\hline Morris, & 1968 & (44) & Secondary, $\quad 400$ & $\uparrow \mathrm{P} / \mathrm{S} \quad(0.2-1.8)$ & $\downarrow 16 \%$ & N.S. & $\downarrow 16 \%$ N.S. \\
\hline Woodhill, & 1978 & (148) & Secondary, 400 & $\uparrow \mathrm{P} / \mathrm{S} \quad(0.8-1.7)$ & $\downarrow 4 \%$ & $\uparrow 50 \%$ & Not reported \\
\hline Hjermann, & 1986 & (138) & Primary, & $\begin{array}{cc}\uparrow \mathrm{P} / \mathrm{S} & (0.3-0.7) \\
\uparrow \mathrm{n}-3 & \text { (Fish) }\end{array}$ & $\downarrow 10 \%$ & $\downarrow 39 \%$ & $\downarrow 44 \%<0.03$ \\
\hline Frantz, & 1989 & $(42)$ & Primary, & $\uparrow \mathrm{P} / \mathrm{S} \quad(0.3-1.6)$ & $\downarrow 15 \%$ & $\uparrow 8 \%$ & $\uparrow 8 \% \quad$ N.S. \\
\hline
\end{tabular}

Prevention through increase in n-3 fatty acids

\begin{tabular}{|c|c|c|c|c|c|c|c|}
\hline Hjermann, & , 1986 & (138) & Primary, $\quad 1232$ & $\begin{array}{cc}\uparrow \mathrm{P} / \mathrm{S} & (0.3-0.7) \\
\uparrow \mathrm{n}-3 & (\text { Fish })\end{array}$ & $\downarrow 10 \%$ & $\downarrow 39 \%$ & $\downarrow 44 \%<0.03$ \\
\hline Dart, & 1989 & (45) & Secondary, 2033 & $\begin{array}{rc}\mathrm{P} / \mathrm{S} & (0.6-0.6) \\
\uparrow \mathrm{n}-3 & (\text { Fish })\end{array}$ & N.S. & $\downarrow 30 \%$ & N.S. \\
\hline Lyon, & $1994-5$ & $(9,10)$ & Secondary, 600 & $\begin{array}{rr}\mathrm{P} / \mathrm{S} & (0.7-0.7) \\
\uparrow \mathrm{n}-3 & (\mathrm{ALA})\end{array}$ & N.S. & $\downarrow 70 \%$ & $\downarrow 73 \%<0.001$ \\
\hline Gissi, & 1999 & (56) & Secondary, 11324 & $\begin{array}{cc}\mathrm{P} / \mathrm{S} & \text { similar } \\
\uparrow \mathrm{n}-3 & (\mathrm{EPA}, \mathrm{DHA})\end{array}$ & N.S. & $\downarrow 20 \%$ & N.S. \\
\hline
\end{tabular}

Fig. 3 The main dietary intervention trials to prevent CHD. Total and cardiovascular (not shown) mortality were significantly lowered only when the intake of n-3 FA was increased. Non fatal MI may be lowered, primarily when the n-3 FA is ALA (the Lyon study) as also observed in recent prospective studies ${ }^{46,47}$. Nevertheless in the Lyon and Hjermann trials the higher intake of vegetables and fruits may have contributed to the observed protective effects. $\mathrm{P} / \mathrm{S}=$ polyunsaturated $/$ saturated fatty acids, chol = cholesterol 
the $\mathrm{P} / \mathrm{S}$ ratio was only $0.7^{31}$ and serum cholesterol lowered by only $10 \%$. Thus the Hjermann trial was the first to really demonstrate a significant reduction in CHD by a somewhat palatable diet more comparable to diet used by populations with low mortality rate from CHD.

Since in the 1980's it was clear that coronary thrombosis was the main factor responsible for myocardial infarction, before undertaking our own trial $^{9}$ we determined first in human populations, what diet was the most efficient to lower platelet reactivity (aggregation, coagulation). As shown in French farmers ${ }^{40,108}$ it was not a diet low in SFA and rich in PUFA, especially in LA even if it was the easiest way to lower serum cholesterol. It was a Mediterranean type diet used in South of France and we reproduced its effects in Moselle, in Eastern France ${ }^{40}$.

The fat composition of the diet to decrease platelet aggregation to all agonists consisted of moderate changes with $10 \%$ of energy from saturated fat, a $\mathrm{P} / \mathrm{S}$ ratio of 0.6 (PUFA, 6\% energy) and a ratio of LA/ALA 5/1. It was not far from the diet used in Crete, associated with the lowest mortality rate from CHD among the 16 groups of the Seven Countries ${ }^{1}$ and the greatest life expectancy in the Western World ${ }^{139}$. It included a somewhat high intake of ALA as shown by the fatty acid composition of cholesterol esters in Crete compared to Netherlands ${ }^{140}$.

In the Lyon trial on 600 coronary patients ${ }^{9,10}$, to stick more closely to the Crete diet, it was advised to the patients to adhere to the following suggestions ${ }^{10}$.

1. more bread,

2. more vegetables and legumes,

3. more fish,

4. less meat (beef, lamb, pork) replaced by poultry,

5. no day without fruit,

6. no more butter and cream, to be replaced by a special margarine made out of rapeseed oil and to switch from sunflower oil or similar oils rich in LA to olive oil or rapeseed oil.

The special margarine used in the intervention trial had been designed already for the Moselle study ${ }^{40}$. Its FA composition (Fig. 1) was very close to that of rapeseed (canola) oil. It is also somewhat similar to that of olive oil.

In Crete, olive oil is used with all meals including breakfast, on bread, with coffee. At present in France, it is difficult to have olive oil with all meals. Thus to have patients accepting to switch from butter and cream to another type of fat, margarine had to be supplied with a composition similar to olive oil. Rapeseed oil was selected because it is the only oil very similar to olive oil but in addition it contains more ALA than olive oil (6-8\% instead of $1 \%$ ) that in Crete is supplied by different foodstuffs such as purslane, snails, walnuts and others.

Concerning dairy products, only cheese, yogurt, fermented dairy products in general, especially low fat, were encouraged. A moderate intake of wine was also suggested.
After a mean follow-up of 27 months, non fatal MI and cardiac death were reduced by more than $70 \%$ with the Mediterranean type diet compared to controls with a prudent diet. Serum cholesterol, triglycerides, HDL and LDL cholesterol, Apoprotein A and B, Lipoprotein(a) were identical in the 2 groups.

In addition, there were 8 sudden deaths in the control group and none in the experimental. Additional thrombotic events such as unstable angina, stroke and thromboembolism were also reduced by more than $70 \%$. By contrast stable angina, more closely related to the severity of atherosclerosis, thus to serum cholesterol, was only reduced by $28 \%$ in the recent evaluation after 4 years $^{141}$.

It can be considered if confirmed, that the Lyon diet heart study reproduces, in France, the striking protection of the Cretans for CHD and also all cause mortality, essentially with an adaptation of their diet since medical treatment was identical in the two groups. As in Crete compared to other Mediterranean groups ${ }^{1}$, serum cholesterol in Lyon was not lower in the experimental group than in the control ${ }^{9,10}$. In the experimental group, the intake of saturated fat was lower (8\% of energy vs 10.6\%) especially stearic acid, as confirmed by the FA composition of plasma. The intake of OLA was higher by $40 \%$ and the ratio of LA/ALA was $23 / 1$ in controls versus 4.5-5.0/1 in the experimental group with an ALA intake of $2 \mathrm{~g} /$ day. The experimental group also consumed more bread, legumes, vegetables and fruits, while fish consumption was similar in the two groups.

A key factor in the protection observed in the experimental group may be the intake of ALA $^{141}$, probably similar to that in Crete as evaluated from the level in plasma ${ }^{140}$. Also of interest is that a high level of ALA has also been found in $\operatorname{Japan}^{142}$ and in Canadian Inuits $^{143}$, two populations known for their protection from CHD usually attributed to fish consumption. It has also been found in 3 prospective studies as the only fatty acid inversely related to non fatal ${ }^{46,47}$ or fatal $\mathrm{MI}^{48}$. ALA supplied under the form of rapeseed oil, was the most efficient FA at least in rat, to prevent ventricular fibrillation and sudden death ${ }^{24,25}$. We found that it was also the only FA associated with lower platelet reactivity ${ }^{40}$ in confirmation of the pioneer work of Owren on platelet adhesiveness $^{144}$

The work of Singh et al., in India, obtained results comparable to the Lyon diet heart study to prevent recurrences after an MI, with a diet rich in vegetables and fruits ${ }^{145}$ or with n-3 FA ${ }^{146}$. Finally, in Finland, between 1972 and 1992, the sharp decline in CHD appears to be the result of changes in the main risk factors, attributed to diet modification.

In brief, these dietary changes consisted:

1. in switching from high fat to low-fat milk, now used by $80 \%$ of the population, 
2. replacing butter on bread by soft margarines,

3. using rapeseed (canola) oil for cooking and in the margarine industry,

4. increasing continuously over the years the consumption of fish and cheese,

5. increasing consumption of fruits $(\times 2)$ and vegetables $(\times 3)$.

Thus the changes in the dietary habits that took place in Finland during the last part of this century were very similar to those of the experimental group in the Lyon diet Heart Study.

Concerning the public health implications of the diet recently designed to effectively prevent $\mathrm{CHD}$, it is interesting to note that such dietary changes at the level of the Finnish population have been associated with an enjoyable decline of 55 to $68 \%$ in the mortality rate from CHD over a period of 20 years. During that period, CHD mortality in Finland, once the highest in the Western World, declined markedly (up to $80 \%$ in $40-50$ years old men) in such a way it is now similar to that of UK or $\mathrm{USA}^{147}$. Apparently it is more than can be explained by the main risk factors ${ }^{115}$ i.e. smoking, blood pressure and cholesterol, the last two being markedly influenced by diet. Of additional interest is that, at least in intervention trials ${ }^{9,145}$, these dietary protective effects occur rapidly i.e. within a few months after diet modification, owing to direct effects on thrombosis and cardiac (sudden) death, independently of serum cholesterol as shown by human and animal studies.

In addition to ALA and other n-3 FA, many nutrients may be involved in the protective effects of diet as summarized in Fig. 4. Of additional interest is that such dietary changes were also associated with a drastic

reduction in cancer mortality, both in Finland and in the Lyon trial $^{51}$.

\section{Abbreviations}

ACAT

ADP

ALA

CHD

DHA

FA

EPA

HDL

LA

LDL

LDL-C

$\mathrm{LP}(\mathrm{a})$

MI

MUFA

n-3 FA

n-6 FA

OLA

PUFA

$\mathrm{P} / \mathrm{S}$

SFA

TC

TFA

UFA

VLDL acetyl CoA cholesterol acyltransferase adenosine diphosphate alpha-linolenic acid coronary heart disease docosahexaenoic acid fatty acids eicosapentaenoic acid high density lipoproteins

linoleic acid low density lipoproteins LDL cholesterol lipoprotein a myocardial infarction monounsaturated fatty acids family of fatty acids derived from alphalinolenic acid (18:3 n-3)

family of fatty acids derived from linoleic acid (18:2 n-6)

oleic acid

polyunsaturated fatty acids

polyunsaturated/saturated fatty acids saturated fatty acids

total cholesterol

trans fatty acids

unsaturated fatty acids

very low density lipoproteins

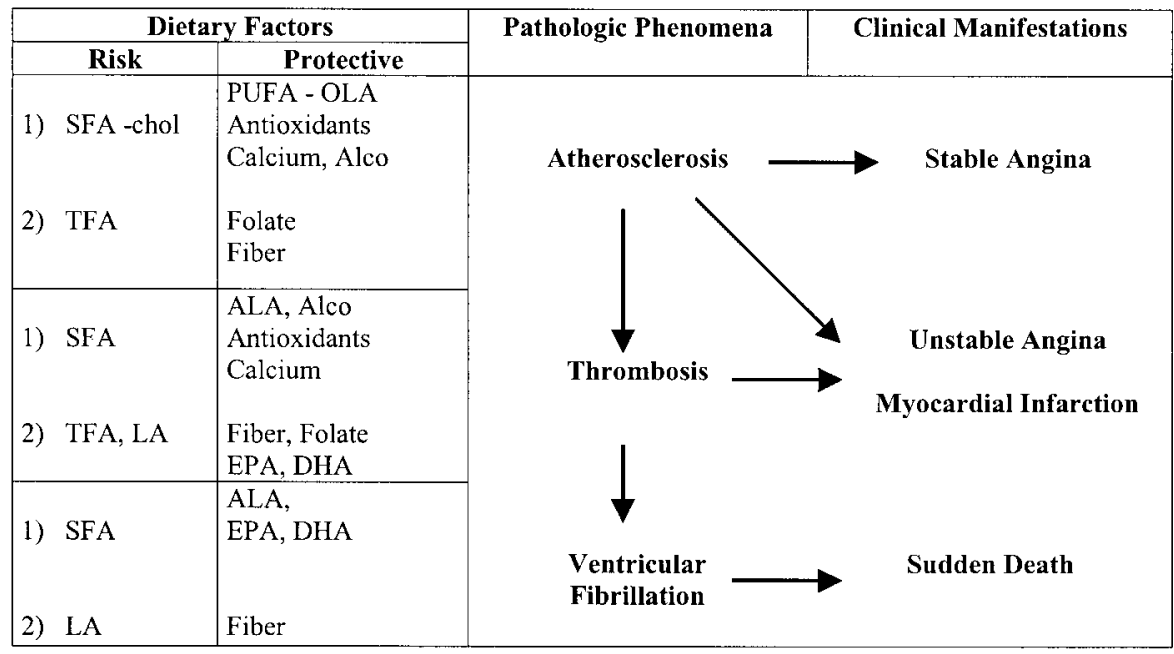

Fig. 4 Nutrients with demonstrated or possible links with CHD clinical manifestations. Evidence: (1) reasonable; (2) to be confirmed. Abbrevations: $A L A=$ alpha-linolenic acid, Alco = alcohol, DHA = docosahexaenoic acid, EPA = eicosapentaenoic acid, $L A=$ linoleic acid, OLA $=$ oleic acid, PUFA $=$ polyunsaturated fatty acids, SFA $=$ saturated fatty acids, TFA = trans fatty acids 


\section{Acknowledgements}

We are grateful to Marie-Laure Marty for the extensive literature searches.

In addition to INSERM, Unit 330, the studies of S. Renaud and his team are partly supported by the Ministry of Agriculture, the 'Fondation pour la Recherche Médicale', the Onidol and the Danone group.

\section{References}

1 Keys A. Coronary heart disease in seven countries. Circulation 1970; 41(Suppl 1): 1-211.

2 Kato H, Tillotson J, Nichaman JZ, Rhoads GG, Hamilton HB. Epidemiologic studies of coronary heart disease and stroke in Japanese men living in Japan, Hawaii and California. Am. J. Epidemiol. 1973; 97: 372-85.

3 Renaud S, de Lorgeril M. Dietary lipids and their relation to ischaemic heart disease: from epidemiology to prevention. J. Intern. Med. 1989; 225(Suppl 1): 39-46.

4 Kromhout D, Menotti A, Blowmberg B, et al. Dietary saturated and trans fatty acids and cholesterol and 25-year mortality from coronary heart disease: the Seven Countries Study. Prev. Med. 1995; 24: 308-15.

5 Caggiula AW, Mustad VA. Effects of dietary fat and fatty acids on coronary artery disease risk and total and lipoprotein cholesterol concentrations: epidemiologic studies. Am. J. Clin. Nutr. 1997; 65(Suppl): 159-610S.

6 Joossens JV, Geboers J, Kesteloot H. Nutrition and cardiovascular mortality in Belgium. Acta Cardiol 1989; 44: $157-182$

7 Shekelle RB, Shryock AM, Paul O, et al. Diet, serum cholesterol, and death from coronary heart disease. The Western Electric Study. N. Engl. J. Med. 1981; 304: 65-70.

8 Kromhout D, de Lezenne Coulander C. Diet, prevalence and 10 year mortality from coronary heart disease in 871 middle-aged men. The Zutphen Study. Am. J. Epidemiol. 1984; 119: 733-741.

9 De Lorgeril M, Renaud S, Mamelle N, et al. Mediterranean alpha-linolenic acid-rich diet in secondary prevention of coronary heart disease. Lancet 1994; 343: 1454-1459.

10 Renaud S, de Lorgeril M, Delaye J, et al. Cretan Mediterranean diet for prevention of coronary heart disease. Am.J. Clin. Nutr. 1995; 61(Suppl): 1360-7S.

11 Kritchevsky D. Role of cholesterol vehicle in experimental atherosclerosis. Am. J. Clin. Nutr. 1970; 23: 1105-10.

12 Mattson FH, Nolen GA, Webb MR. The absorbability of fats of various triglycerides of stearic and oleic acid and the effect of dietary calcium and magnesium. J. Nutr. 1973; 109 1682-7.

13 Renaud S, Ruf JC, Petithory D. The position distribution of fatty acids in palm oil and lard influences their biologic effects in rats. J. Nutr. 1995; 125: 229-37.

14 Kritchevsky D, Moyer AW, Tesar WC, et al. Effect of cholesterol vehicle in experimental atherosclerosis. Am.J. Physiol. 1954; 178: 30-2.

15 Wolfe MS, Sayer JK, Morgan TM, Bullock BC, Rudel LL. Dietary polyunsaturated fat decreases coronary artery atherosclerosis in a pediatric-aged population of African Green monkeys. Arterioscler Thromb. 1994; 14: 587-97.

16 Nordoy A. The influence of saturated fats, cholesterol, corn oil and linseed oil on experimental venous thrombosis in rats. Thromb Diath Haemorrheol 1965; 13: 244-56.

17 Nordoy A, Hamlin JT, Chandler AB, Newland H. The influence of dietary fats on plasma and platelet lipids and ADP induced platelet thrombosis in the rat. Scand $I$. Haematol. 1968; 5: 458-73.
18 Renaud S, Godu J. Induction of large thrombi in hyperlipemic rats by epinephrine and endotoxin. Lab. Invest. 1969; 21: $512-518$.

19 Hornstra G, Vendelmans A. Induction of experimental arterial thrombi in rats. Atherosclerosis 1973; 17: 369-82.

20 Renaud S. Thrombotic, atherosclerotic and lipemic effects of dietary fats in the rats. Angiology, Baltimore 1969; 20: 657-69.

21 Connor WE, Hoak JC, Warner FD. Massive thrombosis produced by fatty acid infusion. J. Clin. Invest. 1963; 42 : 860-6.

22 Gautheron P, Renaud S. Hyperlipemia induced hypercoagulable state in rat. Role of increased activity of platelet phosphatidyl serine in response to certain dietary fatty acids. Thromb. Res. 1972; 1: 353-70.

23 Billman GE, Kang JX, Leaf A. Prevention of ischemiainduced cardiac sudden death by n-3 polyunsaturated fatty acids in dogs. Lipids 1997; 32: 1161-8.

24 Siebert BD, McLennan PL, Woodhouse JA, Charnock JS Cardiac arrhythmia in rats in response to dietary n-3 fatty acids from red meat, fish oil and canola oil. Nutr. Res. 1993; 13: $1407-18$.

25 McLennan PL, Dallimore JA. Dietary canola oil modifies myocardial fatty acids and inhibits cardiac arrhytmias in rats. J. Nutr. 1995; 125: 1003-9.

26 Xiao YF, Gomez AM, Morgan JP, Lederer WJ, Leaf A Suppression of voltage-gated L-type Ca2+ currents by polyunsaturated fatty acids in adult and neonatal rat ventricular myocytes. Proc. Nat. Acad. Sci. USA 1997; 94: 4182-7.

27 Hunter JE, Applewhite TH. Reassessment of trans fatty acid availability in the US diet. Am. J. Clin. Nutr. 1991; 54: 363-9.

28 Hulshof K, Van Erp Baart MA, Anttolainen M, et al. Intake of fatty acids in Western Europe with emphasis on trans fatty acids: the TRANSFAIR study. Europ. J. Clin. Nutr. 1999; 53: 143-57.

29 Willett WC, Stampfer JM, Manson JE. Intakes of trans fatty acids and risk of coronary heart disease among women. Lancet 1993; 341: 581-6.

$30 \mathrm{Hu}$ FB, Stampfer MJ, Manson JE, Rimm E, Colditz GA, Rosner BA, Hennekens CH, Willett WC. Dietary fat intake and the risk of coronary heart disease in women. N. Engl. Med. 1997; 337: 1491-9.

31 Editorial. Trans fatty acids and coronary heart disease: weighing the evidence against hardened fat. Lancet 1995; 345: 269-270.

32 Nicolosi RJ. Trans fatty acids and coronary heart disease risk. Experimental mechanism: formation of atheroma. Am. J. Clin. Nutr. 1995; 62(Suppl): 689S-92S.

33 Kritchevsky D, Davidson LM, Weight M, Kriek NPJ, du Plessis JP. Effect of trans-unsaturated fats on experimental atherosclerosis in Vervet monkeys. Atherosclerosis 1984; 51: 123-33.

34 Toda T, Toda Y, Yamamoto VK, Kummerow FA. Comparative study of atherogenicity of dietary trans, saturated and unsaturated fatty acids on swine coronary arteries. J. Nutr. Sci. Vitaminol. 1985; 31: 233-41.

35 Weigensberg BI, McMillan GC, Ritchie AC. Elaidic acid: effect on experimental atherosclerosis. Arch. Pathol. 1961; 72: 358-66.

36 Katan MB. Commentary on the supplement trans fatty acids and coronary heart disease risk. Am.J. Clin. Nutr. 1995; 62: 518-9.

37 Crawford MA. The balance between alpha-linolenic and linoleic acid. The role of fats in Human Nutrition. In: Brun JP, et al., eds. Chichester: Ellis Horwood, 1985: 62.

38 Gautheron P, Dumont E, Renaud S. Clotting activity of platelet phospholipids in rats and man. Thromb Diath Haemor 1974; 32: 382.

39 Sellmayer A, Danesh U, Weber PC. Modulation of the 
expression of early genes by polyunsaturated fatty acids. Prostagland Leukot EFA 1997; 57: 353-7.

40 Renaud S, Godsey F, Dumont E, Thévenon C, Ortchanian E. Influence of diet modification on platelet function and composition in Moselle farmers. Am. J. Clin. Nutr. 1986; 43: $136-50$.

41 Emken EA, Adlot RO, Gulley RM. Dietary linoleic acid influences desaturation and acylation of deuterium-labeled linoleic and linolenic acids in young adult males. Biochem. Biophys. Acta. 1994; 1213: 277-88.

42 Frantz IDJr, Dawson EA, Ashom PL, et al. Test of effect of lipid lowering by diet on cardiovascular risk. The Minnesota Coronary Survey. Arteriosclerosis 1989; 9: 129-35.

43 Leren P. The Oslo diet heart study. Eleven year report. Circulation 1970; 42: 935-42.

44 Morris JN, Ball KP, Antonis A, et al. Controlled trial of soya bean oil in myocardial infarction. Lancet. 1968; 2: 694-700.

45 Burr ML, Fehily AM, Gilbert JF, et al. Effects of changes in fat, fish, and fiber intakes on death and myocardial reinfarction: diet and reinfarction trial (DART). Lancet 1989; 2: 757-61.

46 Ascherio A, Rimm EB, Giovannucci EL, Spiegelman D, Stampfer MJ, Willett WC. Dietary fat and risk of coronary heart disease in men: cohort follow up study in the United States. BMJ 1996; 313: 84-90.

47 Guallar E, Aro A, Jimenez FJ, et al. Omega-3 fatty acids in adipose tissue and risk of myocardial infarction: the Euramic study. Arterioscler Thromb Vasc. Biol. 1999; 19: 1111-8.

$48 \mathrm{Hu}$ FB, Stampfer MJ, Morison JE, et al. Dietary intake of alpha-linolenic acid and risk of fatal ischaemic heart disease among women. Am. J. Clin. Nutr. 1999; 69: 890-7.

49 Renaud S, Nordoy A. Small is beautiful: $\alpha$-linolenic acid and eicosapentaenoic acid in man. Lancet 1983: 1169.

50 Renaud S. Linoleic acid, platelet aggregation and myocardial infarction. Atherosclerosis 1990; 80: 255-6.

51 De Lorgeril M, Salen P, Martin JL, Monjaud I, Boucher P, Mamelle N. Mediterranean dietary pattern in a randomized trial. Prolonged survival and possible reduced cancer rate. Arch. Intern. Med. 1998; 158: 1181-7.

52 Watanabe S, Sakai N, Yasui Y, et al. A high $\alpha$-linolenate diet suppresses antigen-induced immunoglobin $\mathrm{E}$ response and anaphylactic shock in mice. J. Nutr. 1994; 124: 1566-73.

53 Bang HO, Dyerberg J, Sinclair HM. The composition of Eskimo food in north western Greenland. Am.J. Clin. Nutr. 1980; 33: 2657-61.

54 Kromhout D, Bosschieter EB, de Lezenne Coulander C. The inverse relation between fish consumption and 20 year mortality from coronary heart disease. N. Engl.J. Med. 1985; 312: $1205-9$.

55 Norell SE, Ahlbom A, Feychting M, Pedersen NL. Fish consumption and mortality from coronary heart disease. BMJ 1986; 293: 426.

56 Gissi Prevenzione Investigators. Dietary supplementation with n-3 polyunsaturated fatty acids and vitamin $\mathrm{E}$ after myocardial infarction: results of the Gissi Prevenzione trial. Lancet 1999; 354: 447-53.

57 Leaf A, Weber PC. Cardiovascular effects of n-3 fatty acids. N. Engl. J. Med. 1988; 318: 549-57.

58 Sensaki H, Iwamoto S, Ogura E, et al. Dietary effects of fatty acids on growth and metastasis of KPL-1 human breast cancer cells in vivo and in vitro. Anticancer Res. 1998; 18: 1621-8.

59 Weyman C, Berlin J, Smith AD, Thomson RSH. Linoleic acid as an immunosuppressive agent. Lancet 1975 ; 2: 33-4.

60 Keys A. Serum cholesterol response to dietary cholesterol. Am. J. Clin. Nutr. 1984; 40: 351-9.

61 Grundy SM. Influence of stearic acid on cholesterol metabolism relative to other long-chain fatty acids. Am.J. Clin. Nutr. 1994; 60(Suppl): 986-90S.
62 Kris-Etherton PM, Yu S. Individual fatty acid effects on plasma lipids and lipoproteins: human studies. Am. J. Clin. Nutr. 65(Suppl)1997; : S1628-44.

63 Jacotot B, Sola R, Motta C. Dietary monounsaturated fats and serum HDL. Europ. J. Clin. Nutr. 1991; 45(Suppl): 6669.

64 Tsimikas S, Philis-Tsimikas A, Alexopoulos S, Sigari F, Lee C, Reaven PD. LDL isolated from Greek subjects on a typical diet or from American subjects on an Oleate-supplement diet induces less monocyte chemotaxis and adhesion when exposed to oxidative stress. Arterioscler Thromb. Vasc. Biol. 1999; 87: 403-406.

65 Sola R, Motta C, Maille M, et al. Dietary monounsaturated fatty acids enhance cholesterol efflux from human fibroblasts. Relationship to fluidity, phospholipid fatty acid composition, overall composition and size of HDL 3 . Arterioscler Thromb 1993; 13: 958-66.

66 Roche H, Zampelas A, Knapper JME, et al. Effect of longterm olive oil dietary intervention on postprandial triacylglycerol and factor VII metabolism. Am. J. Clin. Nutr. 1998; 68: $552-60$

67 Ruddock V, Meade TW. Factor VII activity and ischeamic heart disease: fatal and non fatal events. Q.J. Med. 1994; 87: 403-6.

68 Connor WE. Dietary fiber. Nostrum or critical nutrient? $N$. Engl. J. Med. 1990; 322: 193-5.

69 Anderson JW, Story L, Sieling B, Chen WJ, Petro MS, Story J. Hypocholesterolemic effects of oat bran or bean intake for hypercholesterolemic men. Am. J. Clin. Nutr. 1984; 40 $1146-55$.

70 Khaw KT, Barrett Connor E. Dietary fiber and reduce ischemic heart disease mortality rates in men and women: a 12 year prospective study. Am. J. Epidemiol. 1987; 126: 1093-102.

71 Kromhout D. Bosschieter EB and de Lezenne Coulander C. Dietary fiber and 10 year mortality from coronary heart disease, cancer and all causes: the Zutphen Study. Lancet II 1982; 2: 518-21.

72 Pietinen P, Rimm EB, Korhonen P, et al. Intake of dietary fiber and risk of coronary heart disease in a cohort of Finnish Men. Circulation 1996; 94: 2720-7.

73 Rimm EB, Ascherio A, Giovannuci E, Spiegelman D, Stampfer MJ, Willett W. Vegetable, fruit and cereal fiber intake and risk of coronary heart disease among men. JAMA 1996; 275: 447-51.

74 Hallfrisch J, Scholfield DJ, Behall KM. Diets containing soluble oat extracts improve glucose and insulin responses of moderately hypercholesterolemic men and women. $\mathrm{Am}$. J. Clin. Nutr. 1995; 61: 379-84.

75 Simpson HCR, Mann JL, Chakrabarti R. Effect of high fiber diet on hemostatic variables in diabetes. BMJ 1982; 284: 1608-15.

76 Halliwell B. Currents status review: free radicals, reactive oxygen species and human disease: a critical evaluation with special reference to atherosclerosis. Br. J. Exp. Pathol. 1989; 70: 737-57.

77 Witztum JL, Steinberg D. Role of oxidized low density lipoprotein in atherogenesis. J. Clin. Invest. 1991; 88: 178592.

78 Henning JL, Chow CK. Lipid peroxidation and endothelial cell injury: implications in atherosclerosis. Free Radic Biol. Med. 1988; 4: 99-106.

79 Regnström J, Nilsson J, Tornvall P, Landou C, Hamsten A. Susceptibility to low-density lipoprotein oxidation and coronary atherosclerosis in man. Lancet 1992; 339: 1183-6.

80 Reaven PD, Grasse BJ, Trible DL. Effects of linoleate enriched and oleate enriched diets in combination with alpha-tocopherol on the susceptibility of LDL and LDL subfraction to oxidative modification in humans. Arterioscler Thromb 1994; 14: 557-66. 
81 Shahar E. A putative role of dietary omega 3 polyunsaturated fatty acids in oxidative modification of low density lipoprotein. Prostag Leuk Ess Fatty Acids 1993; 48: 397-9.

82 Rimm EB, Stampfer MJ, Ascherio A, Giovannucci E, Colditz GA, Willett WC. Vitamin E consumption and the risk of coronary heart disease in men. Engl. J. Med. 1993; 328: 1450-6.

83 Stampfer MJ, Hennekens CH, Manson JE, Colditz GA, Rosner B, Willett WC. Vitamin E consumption and the risk of coronary heart disease in women. N. Engl. J. Med. 1993; 328: 1444-9.

84 Gey KF, Stähelin HB, Eichholzer M. Poor plasma status of carotene and vitamin $\mathrm{C}$ is associated with higher mortality from ischemic heart disease and stroke. Clin. Invest. 1993; 71: 3-6.

85 Kok FJ, de Bruyn AM, Vermeeren R, et al. Serum selenium, vitamin antioxidants and cardiovascular mortality: a 9 year follow-up in the Netherlands. Am. J. Clin. Nutr. 1987; 45 : $462-8$.

86 Hense HW, Stender M, Bors W, Keil U. Lack of an association between serum vitamin $\mathrm{E}$ and myocardial infarction in a population with high vitamin $\mathrm{E}$ levels. Atherosclerosis 1993; 103: 21-8.

87 Stephens NG, Parsons A, Schofield PM, et al. Randomized controlled trial of vitamin $\mathrm{E}$ in patients with coronary disease: Cambridge Heart Antioxidant Study (CHAOS). Lancet 1996; 347: 781-6.

88 Rapola JM, Virtamo J, Haukla JK, et al. Effect of vitamin E and beta carotene on the incidence of angina pectoris. $J$. Am. Med. Ass. 1996; 275: 693-8.

89 Nagaoka S, Okauchi Y, Urano S, Nagashima U, Mukai R. Kinetic and $a b$ initio study of the pro-oxidant effect of vitamin E. Hydrogen abstraction from fatty acid esters and egg yolk lecithin. J. Am. Chem. Soc. 1990; 112: 8921-4.

90 Kagan VE, Serbinova EA, Forte T, Scita G, Packer L. Recycling of vitamin $\mathrm{E}$ in human low-density lipoproteins. $J$. Lip. Res. 1992; 33: 385-97.

91 Sharma MK, Buettner GR. Interaction of vitamin $C$ and vitamin E during free radical stress in plasma: an ESR study. Free radical Biology and Medicine 1993; 14: 649-56.

92 Hertog MGL, Feskens EJM, Hollman PCH, Katan MB, Kromhout D. Dietary antioxidant flavonoids and risk of coronary heart disease: the Zutphen elderly study. Lancet. 1993; 342: 1007-11.

93 Knekt P, Järvinen R, Reunanen A, Maatela J. Flavonoids intake and coronary mortality in Finland: a cohort study. BMJ 1996; 312: 478-81.

94 Hertog AG, Kromhout D, Aravanis C, et al. Flavonoid intake and long-term risk of coronary heart disease and cancer in the Seven Countries Study. Arch. Intern. Med. 1995; 155: 381-6.

95 Mc Cully KS. Vascular pathology of homocysteinemia: implications for pathogenesis of arteriosclerosis. Am. J. Pathol. 1969; 56: 111-28.

96 Clarke R, Daly L, Robinson K, et al. Hyperhomocysteinemia: an independent risk factor for vascular disease. $N$. Engl. J. Med. 1991; 321: 1149-55.

97 Mayer EL, Jacobsen DW, Robinson K. Homocysteine and coronary arteriosclerosis. J. Am. Coll. Cardiol. 1996; 27: $517-27$.

98 Torbek M, Kopeiczna-Grezebieniak E, Drozdz M, Wieczorek M. Increased lipid peroxidation as a mechanism of methionine induced atherosclerosis in rabbits. Atherosclerosis 1995; 115: 217-24.

99 Brattstrom LE, Israelsson B, Norrving B, et al. Impaired homocysteine metabolism in early onset cerebral and peripheral occlusive arterial disease: effects of pyridoxine and folic acid treatment. Atherosclerosis 1990; 81: 51-60.

100 Ubbink JB, Vermaak WJH, Van Der Merwe A, et al. Vitamin requirements for treatment of hyperhomocysteinemia in humans. J. Nutr. 1994; 124: 1927-33.

101 Rimm EB, Willett WC, Hu FB, et al. Folate and vitamin B6 from diet and supplements in relation to risk of coronary heart disease among women. JAMA 1998; 279: 359-64.

102 Olszewski AJ, Mc Cully KS. Fish oil decreases serum homocysteine in hyperlipemic men. Coron Art Dis 1993; 4: 53-60.

103 Masironi R, Pisa Z, Clayton D. Myocardial infarction and water hardness in the WHO myocardial registry network. Bull WHO 1979; 57: 291-9.

104 Shaper AG, Packham RF, Pocock SJ. The British Regional Heart study. J. Environm. Pathol. Toxicol. 1980; 4: 89.

105 Comstock GN. The epidemiologic perspective Water hardness and cardiovascular disease. J. Environm. Path. Toxicol. 1980; 4: 9 .

106 Bhattacharyya AK, Thera C, Anderson JT, Grande F, Keys A. Dietary calcium and fat. Effects on serum lipids and fecal excretion of cholesterol and its degradation products in man. Am. J. Clin. Nutr. 1969; 22: 1161.

107 Yacowitz H, Fleischman AI, Raichelson RI. Effects of oral calcium upon serum lipids in man. BMJ 1965; 1: 1352.

108 Renaud S, Morazain R, Godsey F, et al. Nutrients, platelet function and composition in nine groups of French and British farmers. Atherosclerosis 1986; 60: 37-48.

109 Renaud S, Ciavatti M, Thevenon C, Ripoll JP. Protective effects of dietary calcium and magnesium on platelet function and atherosclerosis in rabbits fed saturated fat. Atherosclerosis 1983; 47: 187.

110 Renaud S. Dietary fatty acids and platelet reactivity in relation to coronary heart disease. Proc on the Effects of Dietary Fatty Acids on Serum Lipoproteins. In: Nicolosi RJ, ed. Washington: American Heart Association, 1989: 125.

111 Mc Carron DA, Morris CD, Henry HJ, Stanton JL. Blood pressure and nutrient intake in the United States. Science 1984; 224: 1392-8.

112 Witteman JCM, Willett WC, Stampfer MJ, et al. A prospective study of nutritional factors and hypertension among US women. Circulation 1989; 80: 1320-1327. Nutrition 1985; 11: 409-17.

113 Vartiainen E, Puska P, Pekkanen J, Tuomilehto J, Jousilahti P. Changes in risk factors explain changes in mortality from ischaemic heart disease in Finland. BMJ 1994; 309: 23-27.

114 Grobbe DE, Rimm EB, Keil U, Renaud S. Alcohol and the Cardiovascular System. In Macdonald I ed. Healt issues related to alcohol consumption. ILSI. Blackwell Science 1999:125-179.

115 Suhonen O, Aromas A, Reunanen A, Knekt P. Alcohol consumption and sudden coronary death in middle-aged Finnish men. Acta. Med. Scan. 1987; 221: 335-341.

116 Kauhanen J, Kaplan GA, Goldberg DE, et al. Beer binging and mortality: results from the Kuopio ischemic heart disease risk factor study, a prospective population based study. BMJ 1997; 315: 846-851.

117 Rimm EB, Giovannucci E, Willet WC, et al. Alcohol and mortality. Lancet. 1991; 338: 1073-1074.

118 Renaud S, Gueguen R, Siest G, Salamon R. Wine, beer and mortaltiy in middle-aged men from Eastern France. Arch. Intern. Med. 1999; 159: 1865-1870.

119 Gronbaek M, Dels A, Sorensen TIA, Becker U, Schnohr P, Jensen G. Mortality associated with moderate intakes of wine, beer or spirits. BMJ 1995; 310: 1165-9.

120 Gronbaek M, Becker U, Johansen D, Tonneson H, Jensen G, Sorensen TIA. Population based cohort study of the association between alcohol intake and cancer of upper digestive tract. BMJ 1995; 317: 844-8.

121 Jang M, Cal L, Udearl GO, et al. Cancer chemopreventive activity of resveratrol, a natural product derived from grapes. Science 1997; 275: 218-20.

122 Williams PT. Interactive effects of exercise, alcohol and 
vegetarian diet on coronary artery disease risk factors in 9242 runners: The National Runner's Health Study. Am. J. Clin. Nutr. 1997; 66: 1197-206.

123 Langer RD, Criqui MH, Reed DM. Lipoproteins and blood pressure as biologic pathways for the effect of moderate alcohol consumption on coronary heart disease. Circulation 1992; 85: 910-5.

124 Yano K, Rhoads GG, Kagan A. Coffee, alcohol and risk of coronary heart disease among Japanese men living in Hawaii. N. Engl. J. Med. 1977; 297: 405-9.

125 Renaud S, Ruf JC. Effects of alcohol on platelet functions. Clin. Chim. Acta. 1996; 246: 77-89.

126 Hillbom M, Kangasaho M, Hjelm-Jäger M. Platelet aggregation and thromboxane B2 formation after ethanol abuse: is there a relationship to stroke? Acta. Neurol. Scand. 1984; 70: $432-7$.

127 Ruf JC, Berger JL, Renaud S. Platelet rebound effect of alcohol withdrawal and wine drinking in rats. Relation to tannins and lipid peroxidation. Arterioscler Thromb. Vasc. Biol. 1995; 1: 140-4.

128 Renaud S, Beswick AD, Fehily AM, Sharps DS, Elwood PC. Alcohol and platelet aggregation: the Caerphilly Prospective Heart Disease Study. Am. J. Clin. Nutr. 1992; 55: 1012-7.

129 Rand ML, Packham MA, Kinlough-Rathbone RL, Mustard JF. Effects of ethanol on pathways of platelet aggregation in vitro. Thromb Haemost 1988; 59: 383-7.

130 Zucker MB, Peterson J. Inhibition of adenosine diphosphate-induced secondary aggregation and other platelet functions by acetylsalicylic acid ingestion. Proc. Soc. Exp. Biol. Med. 1968; 127: 547-551.

131 Steering Committee of the Physician's Health Study Research Group. Final report on the aspirin component of the ongoing Physician's Health Study. N. Engl.J. med. 1989; 3212: $129-35$.

132 Report of the Dietary Guidelines Advisory Committes on the Dietary Guidelines for Americans, to the Secretary of Agriculture and the Secretary of Health and Human Services. Springfield, VA: US Dept of Commerce, National Technical Information Service 1995.

133 Woollett LA, Dietshy JM. Effect of long-chain fatty acids on low-density lipoprotein cholesterol metabolism. Am. J. Clin. Nutr. 1994; 60(Suppl): 991-6S.

134 Keys A, Anderson JT, Grande F. Serum cholesterol response to changes in diet IV Particular saturated fatty acids in the diet. Metabolism 1965; 14: 776-86.

135 Hegsted DM, Ausman LM, Johnson JA, Dollal GE. Dietary fat and serum lipids: an evaluation of the experimental data. Am. J. Clin. Nutr. 1993; 57: 875-83.

136 Mensik RP, Katan MB. Effect of dietary fatty acids on serum lipids and lipoproteins. Arterioscler Thromb 1992; 12: 911-9.

137 Derr J, Kris-Etherton PM, Pearson TA, Seligson FH. The role of fatty acid saturation on plasma lipids, lipoproteins and apolipoproteins: II The plasma total and low-density lipoprotein cholesterol response of individual fatty acids. Metabolism 1993; 42: 130-4.

138 Hjermann I, Holme I, Leren P. Oslo study diet and antismoking trial. Results after 102 months. Am. J. Med. 1986; 80(suppl 2A): 7-11.

139 Blackburn H. The low risk coronary male. Am. J. Cardiol. 1986; 58: 161.

140 Sandker GN, Kromhout D, Aravanis C, et al. Serum cholesteryl ester fatty acids and their relation with serum lipids in elderly men in Crete and the Netherlands. Eur. J. Clin. Nutr. 1993; 47: 201-8.

141 De Lorgeril M, Salen P, Martin JL, Monjaud I, Delaye J, Mamelle N. Mediterranean diet, traditional risk factors and the rate of cardiovascular complications after myocardial infarction. Circulation 1999; 99: 779-85.

142 Kagawa Y, Nishizawa M, Suzuki M, et al. Eicosapolyenoic acid of serum lipids of Japanese islanders with low incidence of cardiovascular diseases. J. Nutr. Sci. Vitaminol. 1982; 28: 441-53.

143 Innis SM. Sources of omega 3 fatty acids in arctic diets. In: Galli C, Simopoulos AP, eds. Dietary omega 3 and omega 6 fatty acids. Biological effects and nutritional essentially. New York: Plenum Press, 1989: 135-46.

144 Owren PA, Hellem AJ, Odegnard A. Linolenic acid for the prevention of thrombosis and myocardial infarction. Lancet 1964; 2: 975-9.

145 Singh RB, Rastogi SS, Verma R, et al. An Indian experiment with nutritional modulation in acute myocardial infarction. Am. J. Cardiol. 1992; 69: 879-85.

146 Singh RB, Niaz MA, Sharma JP, Kumar R, Rastogi V, Mashiri M. Randomized, double-blind, placebo-controlled trial of fish oil and mustard oil in patients with suspected acute myocardial infarction; the Indian experiment of infarct survival. Cardiovasc. Drugs. Ther. 1997; 11: 485-91.

147 Beaglehole R. International trends in coronary heart disease mortality and incidence rates. J. Cardiol Risk 1999; 6: 63-8.

148 Woodhill JM, Palmer AJ, Leelarthaepin B, McGilchrist C, Blacket RB. Low cholesterol in secondary prevention of coronary heart disease. Adv. Exper. Med. Biol. 1978; 209: $317-31$. 